\title{
ZONEAMENTO DO RISCO DE INUNDAÇÃO DO RIO VACACAÍ NO MUNICÍPIO DE SÃO GABRIEL, RS
}

\author{
ZONING THE RISK OF FLOODING VACACAÍ RIVER, SÃO \\ GABRIEL CITY, RS
}

\author{
Romario Trentin \\ Professor Dr. do Dpto. Geociências UFSM \\ romario.trentin@gmail.com \\ Luís Eduardo de Souza Robaina \\ Professor Dr. do Dpto. Geociências UFSM \\ lesrobaina@yahoo.com.br \\ Vanessa Salvade Silveira \\ Graduanda em Geografia pela UFSM \\ vanessasalvade@gmail.com
}

\begin{abstract}
Resumo: O município de São Gabriel, no Estado do Rio Grande do Sul, possui mais de $80 \%$ de sua população na área urbana e, parte desta população se localiza no entorno do Rio Vacacaí e tem sido afetada seguidamente por eventos de inundação. A metodologia do trabalho busca analisar e identificar os aspectos físicos e humanos da paisagem em estudo em relação a sua problemática. Neste trabalho são apresentados os resultados sobre a análise espaço-temporal das inundações, a suscetibilidade às inundações, o perigo de inundação, a vulnerabilidade à inundação e o zoneamento das áreas de risco de inundação pelo Rio Vacacaí no município de São Gabriel. A partir da análise dos trinta anos verificou-se que em dezesseis anos apresentam registros de inundações. No total destes dezesseis anos de eventos foram registrados trinta e dois casos em que a população foi afetada com as inundações. Através do cruzamento do zoneamento do perigo de ocorrência do evento e da vulnerabilidade da população foram identificados 4 graus de risco que atingem a área urbana do município de São Gabriel, sendo eles, baixo, médio, alto e muito alto. O baixo risco encontra-se no bairro Vila Maria, o médio risco ocorre no bairro Baltar, o alto risco ocorre nos bairros Baltar e Menino Jesus e, o muito alto risco encontra-se no bairro Menino Jesus.
\end{abstract}

Palavras-chave: São Gabriel, inundação, perigo, vulnerabilidade, risco.

\begin{abstract}
The municipality of São Gabriel, state of Rio Grande do Sul, has more than $80 \%$ of its population in the urban area and part of this population is located in the vicinity of Rio Vacacaí and has subsequently been affected by flood events. The methodology of the work seeks to analyze and identify the physical and human landscape of the study in relation to their problems. This paper presents the results on the spatio-temporal analysis of floods. From the analysis of the thirty years it was found that in sixteen years have records of flooding. A total of sixteen years of events were recorded thirty-two where the population was affected with floods. Through zoning crossing the hazard of occurrence of the event and the vulnerability of the population were identified 4 degrees of risk affecting the urban area of the São Gabriel city, namely, low, medium, high and very high. The low risk found in Vila Maria, the medium risk occurs in the neighborhood Baltar, the high-risk neighborhoods is Baltar and Menino Jesus and the very high risk is found in neighborhood Menino Jesus.
\end{abstract}

Keywords: São Gabriel, flood, hazard, vulnerability and risk.

Geo UERJ - Ano 15, nº. 24, v. 1, $1^{\circ}$ semestre de 2013 p. 161-180

ISSN: 1415-7543 E-ISSN: 1981-9021

http://www.e-publicacoes.uerj.br/index.php/geouerj 


\section{INTRODUÇÃO}

A relação estabelecida entre a dinâmica dos fenômenos naturais adversos e a ocupação antrópica resulta no surgimento de áreas ou zonas de risco, onde, muitas vezes, se registram desastres naturais de significativa dimensão com danos e perdas sociais e econômicas.

Os desastres naturais, segundo Alcántara-Ayala (2002), ocorrem em todo o mundo, mas o seu impacto é maior em países em desenvolvimento, onde as populações com menores condições sociais e econômicas têm como resultado grandes perdas, principalmente humanas, além da elevada dificuldade da reconstrução pós-desastre.

Mattedi e Butzke (2001) destacam ainda que a ocorrência dos desastres naturais muitas vezes reflete a interface das relações sociedade-natureza, onde observamos a complexa relação de interação entre as pessoas e os eventos naturais adversos, dessa forma, a análise dos desastres e riscos naturais deve levar em consideração tanto a dinâmica dos sistemas ambientais quanto dos sistemas sociais.

Peloggia (1998) salienta que as ocupações inadequadas não ocorrem por falta de informação, mas por obrigatoriedade diante de um quadro de miséria e impossibilidade de acesso a terra. Assim sendo, as áreas de risco surgem como uma interação do meio natural com o meio social. Conforme o autor, o meio natural impõe obstáculos para a ocupação de certas áreas, mas é o meio social, ao ocupar as áreas naturalmente susceptíveis, que acaba desencadeando o surgimento do risco e potencializando a ocorrência de desastres.

O processo de extravasamento das águas do leito normal de um rio é um fenômeno natural. Com a ocupação urbana na planície de inundação dos canais fluviais, este processo acaba por se chamar desastre natural conforme Alcántara-Ayala (2002), pois a população sofre interferência, ou seja, causa prejuízos financeiros e sociais aos moradores que, em geral, são menos favorecidos socioeconomicamente.

Este trabalho tem como objetivo identificar, fazer um zoneamento e mapear as áreas urbanas afetadas por inundações no município de São Gabriel, localizado na região central do estado do Rio Grande do Sul a 320 quilômetros de Porto Alegre (Figura 1). 
Segundo dados do IBGE (2010), o município apresenta uma população total de 60.508 habitantes, com 53.860 habitantes (mais de 80\%) na área urbana. Parte desta população situa-se no entorno do Rio Vacacaí e tem sido afetada seguidamente por eventos de inundação como mostra o levantamento realizado por Reckziegel (2007).

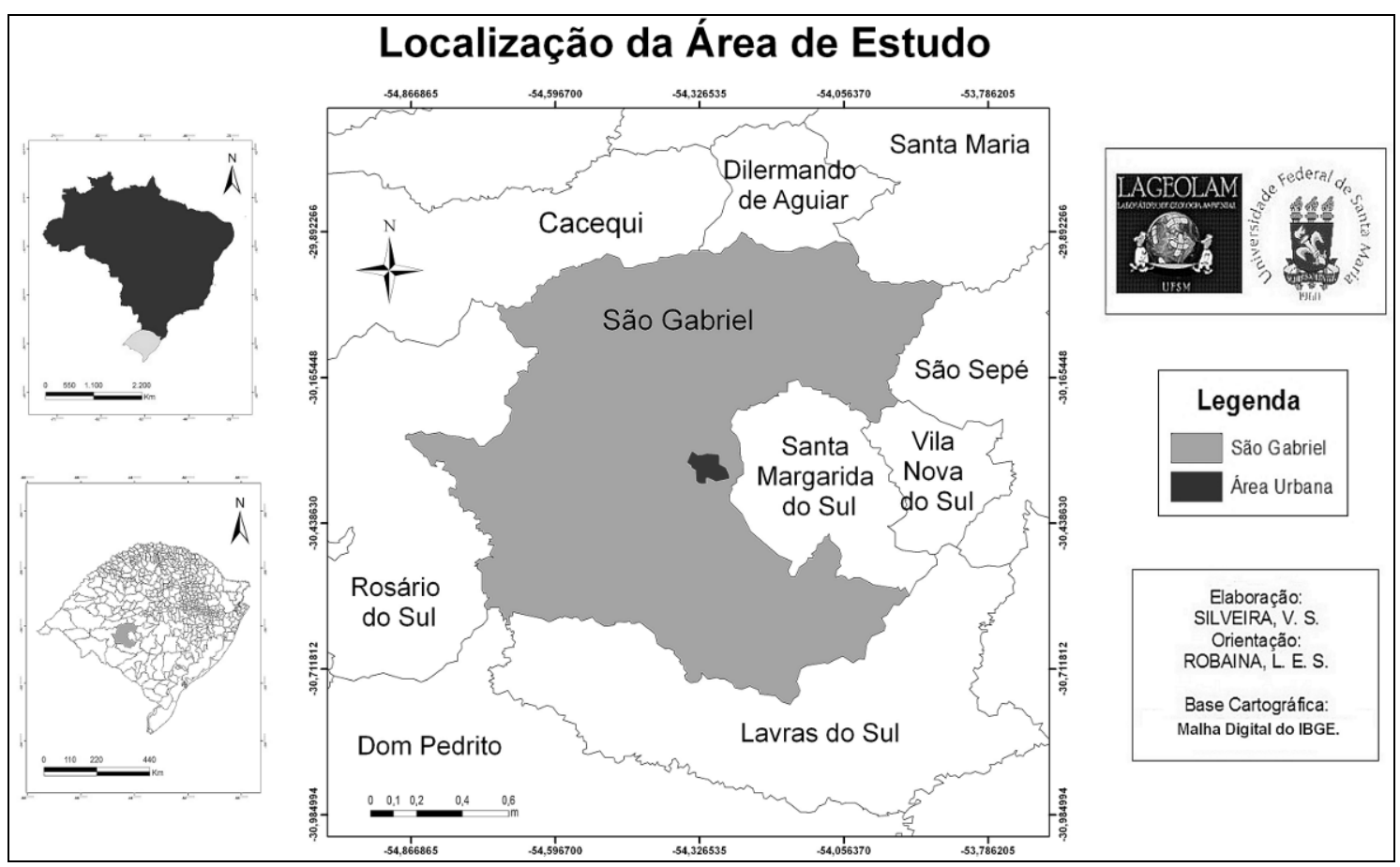

Figura 1: Mapa de localização do município de São Gabriel, RS.

\section{BASES CONCEITUAIS}

Conforme o Ministério das Cidades / IPT (2007), a inundação "representa o transbordamento das águas de um curso d'água, atingindo a planície de inundação ou área de várzea".

Segundo a United Nations International Strategy for Disaster Reduction -(UNISDR 2002), as inundações e enchentes são problemas geoambientais derivados de fenômenos ou perigos naturais de caráter hidrometeorológico ou hidrológico, ou seja, aqueles de natureza atmosférica, hidrológica ou oceanográfica. Sabe-se, hoje, que as inundações estão relacionadas com a quantidade e a intensidade da precipitação atmosférica (SOUZA, 1998, apud TOMINAGA, SANTORO \& AMARAL, 2009). 
Castro (2003) classifica as inundações em função do padrão evolutivo como: enchentes ou inundações graduais, enxurradas ou inundações bruscas, alagamentos e inundações litorâneas.

$\mathrm{Na}$ inundação gradual ou enchente, as águas elevam-se de forma paulatina e previsível; mantêm-se em situação de cheia durante algum tempo e, a seguir, escoam-se gradualmente. Normalmente, as inundações graduais são cíclicas e nitidamente sazonais. Relacionam-se muito mais com períodos demorados de chuvas contínuas do que com chuvas intensas e concentradas. $O$ fenômeno caracteriza-se por sua abrangência e grande extensão.

As inundações bruscas ou enxurradas são provocadas por chuvas intensas e concentradas em regiões de relevo acidentado, caracterizando-se por produzirem súbitas e violentas elevações dos canais, os quais se escoam de forma rápida e intensa. As enxurradas são típicas de regiões acidentadas e normalmente ocorrem em bacias ou subbacias de médio e pequeno porte.

Os alagamentos são águas acumuladas no leito das ruas e nos perímetros urbanos por fortes precipitações pluviométricas em cidades com sistemas de drenagem deficientes. Nos alagamentos, o extravasamento das águas depende muito mais de uma drenagem deficiente, que dificulta a vazão das águas acumuladas, do que das precipitações locais.

Tucci (2005) apresenta uma tipologia com base no escoamento pluvial que pode produzir inundações e impactos nas áreas urbanas devido a dois processos, que ocorrem isoladamente ou combinados: inundações em áreas ribeirinhas e/ou inundações devido à urbanização.

As inundações de áreas ribeirinhas são as naturais que ocorrem no leito maior dos rios, devido à variabilidade temporal e espacial da precipitação e do escoamento na bacia hidrográfica. Já as inundações, devido à urbanização, são as que ocorrem na drenagem urbana devido ao efeito da impermeabilização do solo, canalização do escoamento ou obstruções ao escoamento.

Neste trabalho, a inundação é definida como o transbordamento das águas do canal do rio Vacacaí para sua planície aluvial dentro da área urbana, ou seja, podendo causar algum dano real ou potencial.

Geo UERJ - Ano 15, nº. 24, v. 1, $1^{\circ}$ semestre de 2013 p. 161-180

ISSN: 1415-7543 E-ISSN: 1981-9021

http://www.e-publicacoes.uerj.br/index.php/geouerj 
As definições de suscetibilidade, perigo, vulnerabilidade e risco, muitas vezes, confundem-se. Assim, é fundamental a definição dos termos como base para compreensão teórica do assunto.

Os estudos de suscetibilidade antecedem a avaliação do perigo. A suscetibilidade corresponde à possibilidade de ocorrência de um determinado evento na área analisada, compreendido através de parâmetros que definem uma possibilidade real, como é o caso de registros históricos de inundações em determinados bairros, onde se identificam as áreas inundadas e os períodos de recorrência.

Segundo Julião et al. (2009), a suscetibilidade pode ser entendida como a propensão para uma área ser afetada por um determinado perigo, em tempo indeterminado, sendo avaliada através dos fatores de predisposição para a ocorrência dos processos ou ações. Dessa forma, as cartas ou mapas de suscetibilidade representam a incidência espacial dos perigos.

O termo "perigo" é usado com o mesmo significado utilizado por Ojeda (1997), definindo como a possibilidade de ocorrência de um fenômeno perigoso, em um determinado período de tempo em uma dada área. No que se refere aos perigos classificados como naturais UNDRO (1979) indica que correspondem à probabilidade de ocorrência, dentro de um período de tempo específico em uma determinada área, de um fenômeno natural potencialmente danoso.

A avaliação do perigo de inundação utilizada nesta pesquisa é entendida através da proposta de Deyle et al. (1998), que corresponde ao processo de estimar a extensão geográfica do perigo, a sua magnitude (intensidade) e a probabilidade de ameaça aos interesses humanos.

A vulnerabilidade é um dos conceitos mais complexos, devido à sua ligação com o lado social dos eventos. Veyret (2007) afirma que "a ocorrência do evento tem consequiências para as populações e os bens, seus efeitos podem afetar mais ou menos fortemente o funcionamento das sociedades humanas e dos ecossistemas". Assim como, Dauphiné (2001 apud VEYRET, 2007) assinala que a vulnerabilidade é algo que "exprime o grau das consequiências previsíveis geradas por um fenômeno natural e que podem afetar o alvo".

Geo UERJ - Ano 15, n⿳. 24, v. 1, $1^{\circ}$ semestre de 2013 p. 161-180 ISSN: 1415-7543 E-ISSN: 1981-9021 http://www.e-publicacoes.uerj.br/index.php/geouerj 
Entende-se por vulnerabilidade, basicamente, a concepção de Alcántara-Ayala (2002), que pode ser definida como a propensão de um elemento em risco a qualquer tipo de perigo natural a sofrer diferentes graus de perda ou de dano em função da sua particularidade social, fraquezas econômicas, culturais e políticas.

O risco, portanto, dá-se como um termo que engloba os demais, ou seja, o risco é o produto dá relação do perigo com a vulnerabilidade. Para melhor esclarecimento, temse a definição dada pelo Instituto Geológico de São Paulo que compreende o risco como sendo a expressão: $\mathrm{R}($ risco $)=\mathrm{P}($ perigo $) \times \mathrm{V}$ (vulnerabilidade) $\times \mathrm{D}($ dano $)$.

\section{PROCEDIMENTOS METODOLÓGICOS}

Os dados de ocorrência foram obtidos com a pesquisa documental de uma série histórica de 30 anos por meio do levantamento das inundações do Rio Vacacaí, junto à prefeitura, publicadas no Jornal Imparcial, consultados os levantamentos realizados por Reckziegel (2007) e na Defesa Civil Estadual. A pesquisa, no período entre 1980 e 2009, permitiu obter informações referentes à data de ocorrência das inundações e dos locais atingidos por meio da identificação de ruas e bairros.

Os dados cartográficos adquiridos para a pesquisa foram utilizados para compor a base cartográfica do mapeamento temático das áreas de suscetibilidade e perigo de inundação. Os dados cartográficos corresponderam ao levantamento de dados topográficos, imagens de satélites de alta resolução obtidas de fontes diversas disponibilizadas pelo software Google Earth Pro, através da organização de mosaico da área e posterior georreferenciamento.

Os dados topográficos foram obtidos com base nas cartas topográficas com escala 1:2.000 com curvas de nível com equidistância de um metro disponibilizadas pela prefeitura municipal de São Gabriel. Trabalhos de campo com equipamentos de posicionamento (GPS), nos bairros de registro de eventos, permitiram determinar a área urbana afetada e caracterizar a população que sofre os danos.

A elaboração dos mapas utiliza ferramentas de geoprocessamento elaboradas no software ArcGis 10.

Geo UERJ - Ano 15, no . 24, v. 1, $1^{\circ}$ semestre de 2013 p. 161-180

ISSN: $1415-7543$ E-ISSN: 1981-9021

http://www.e-publicacoes.uerj.br/index.php/geouerj 
O perigo de inundações foi determinado a partir do cruzamento entre as variáveis: frequência dos eventos, mapa de suscetibilidade determinado pela identificação da planície de inundação, e mapa da área urbana.

A partir da integração dessas informações foram definidos dois diferentes níveis de perigo de inundação em termos de probabilidade espacial e temporal na área de estudo:

Alto Grau de Perigo- áreas urbanas na planície de inundação com alta probabilidade temporal e espacial de serem atingidas por inundações;

Baixo Grau de Perigo - áreas urbanas na planície de inundação com alta probabilidade temporal e espacial de serem atingidas por inundações.

\section{Vulnerabilidade a Inundações}

Conforme sugere o Ministério das Cidades (2007), a avaliação da vulnerabilidade compreende a análise do padrão construtivo considerando-se, basicamente duas tipologias construtivas: a) alta vulnerabilidade de acidentes - baixo padrão construtivo onde predominam moradias construídas com madeira ou restos de material com baixa capacidade de resistir ao impacto de processos hidrológicos; b) baixa vulnerabilidade de acidentes - médio a bom padrão construtivo onde predominam moradias construídas em alvenaria com boa capacidade de resistir ao impacto de processos hidrológicos.

Os dados do padrão construtivo das residências e a infraestrutura pública disponível foram apurados através de levantamento em campo, por avaliação empírica, estabelecendo-se características que predominavam por determinadas áreas ou zonas.

Para a avaliação do padrão construtivo habitacional foi considerado o material utilizado nas construções e o estado de conservação das mesmas: casas construídas em alvenaria, em madeira ou com outro material; casas aparentando serem construídas de acordo com normas técnicas de engenharia ou aparentando serem autoconstruídas por seus moradores (OLIVEIRA, 2004, p. 87). Nesse sentido, procurou-se avaliar a capacidade de resistência das unidades habitacionais ao impacto dos processos hidrológicos. 
Ainda, como fator de fragilidade social, foi também considerada a infraestrutura pública disponível, assim, foi avaliado a estrutura das vias com relação a existência ou não de calçamento, pavimento ou apenas chão, iluminação pública e água encanada. $\mathrm{O}$ esgotamento não foi avaliado.

Para se estabelecer o grau de vulnerabilidade com relação ao padrão construtivo e a infraestrutura pública disponível, utilizamos três tipologias e, nesse sentido temos:

Baixo Grau de Vulnerabilidade: bom padrão construtivo, onde predominam casas de alvenaria, em bom estado de conservação, ruas calçadas ou pavimentadas;

Médio Grau de Vulnerabilidade: médio padrão construtivo, onde predominam casas de madeira e casas antigas pouco conservadas, casas de alvenaria inacabadas, alternância entre ruas calçadas e de chão;

Alto Grau de Vulnerabilidade: padrão construtivo precário, com predomínio de casas pequenas, de alvenaria ou de madeira aparentando autoconstrução, casa com material alternativo, casas sem conservação ou manutenção, ruas de chão.

\section{Risco de Inundações}

O risco de inundações foi determinado a partir do cruzamento do zoneamento e mapa de perigo e de vulnerabilidade. A expressão utilizada para geração do mapa de risco de inundação foi:

$$
\mathrm{R}=\mathrm{P} \times \mathrm{V}
$$

onde, "P" corresponde ao Perigo de inundação, o "V" corresponde à Vulnerabilidade a inundações, conforme Quadro 1. O Quadro 2 apresenta a descrição dos diferentes graus de risco.

Quadro 1 - Relação entre perigo e vulnerabilidade indicando os graus de risco

\begin{tabular}{|c|c|c|c|}
\hline Perigo $\backslash$ Vulnerabilidade & Vulnerabilidade Baixa & Vulnerabilidade Média & Vulnerabilidade Alta \\
\hline Perigo Baixo & Risco Baixo & Risco Médio & Risco Alto \\
\hline Perigo Alto & Risco Médio & Risco Alto & Risco Muito Alto \\
\hline
\end{tabular}


Quadro 2: Descrição e peso dos graus de risco à inundações

\begin{tabular}{|c|c|}
\hline Classe & Descrição \\
\hline $\begin{array}{c}\text { Muito } \\
\text { Alto }\end{array}$ & $\begin{array}{c}\text { Áreas urbanas com alta probabilidade de ocorrência de inundações, onde são } \\
\text { esperadas altas ou muito altas consequências de danos a prejuízos. }\end{array}$ \\
\hline Alto & $\begin{array}{r}\text { Áreas urbanas com alta probabilidade de ocorrência de inundações, onde são } \\
\text { esperadas médias consequências de danos a prejuízos. }\end{array}$ \\
\hline Médio & $\begin{array}{c}\text { Áreas urbanas com baixa probabilidade de ocorrência de inundações, mas que } \\
\text { são esperadas médias ou altas consequências de danos e prejuízos; ou Áreas } \\
\text { urbanas com alta probabilidade de ocorrência de inundações, mas são } \\
\text { esperadas baixos danos e prejuízos . }\end{array}$ \\
\hline Baixo & $\begin{array}{r}\text { Áreas urbanas com baixa probabilidade de ocorrência de inundações, onde são } \\
\text { esperadas baixas consequências de danos a prejuízos. }\end{array}$ \\
\hline
\end{tabular}

\section{RESULTA DOS E DISCUSSÃO}

Neste segmento, são apresentados os resultados sobre a análise espaço-temporal das inundações, a suscetibilidade às inundações, o perigo de inundação, a vulnerabilidade à inundação e o zoneamento das áreas de risco de inundação pelo Rio Vacacaí no município de São Gabriel.

\section{Análise Espaço-Temporal das Inundações}

O levantamento realizado sobre a ocorrência de inundações, na cidade de São Gabriel, entre os anos de 1980 a 2009 determinou dezesseis anos de com eventos, com registro de trinta e dois casos em que a população foi afetada (Figura 2).

Os anos com maior incidência de eventos de inundações foram 1984 e 1998 que apresentaram quatro eventos cada, ou seja, foram os anos mais expressivos nestes trinta anos. Já os anos de 1983, 2001 e 2002 apresentaram três eventos. Em todos eles, foi decretado, em pelo menos um dos eventos, situação de emergência.

Geo UERJ - Ano 15, no. 24, v. 1, $1^{\circ}$ semestre de 2013 p. 161-180

ISSN: 1415-7543 E-ISSN: 1981-9021

http://www.e-publicacoes.uerj.br/index.php/geouerj 


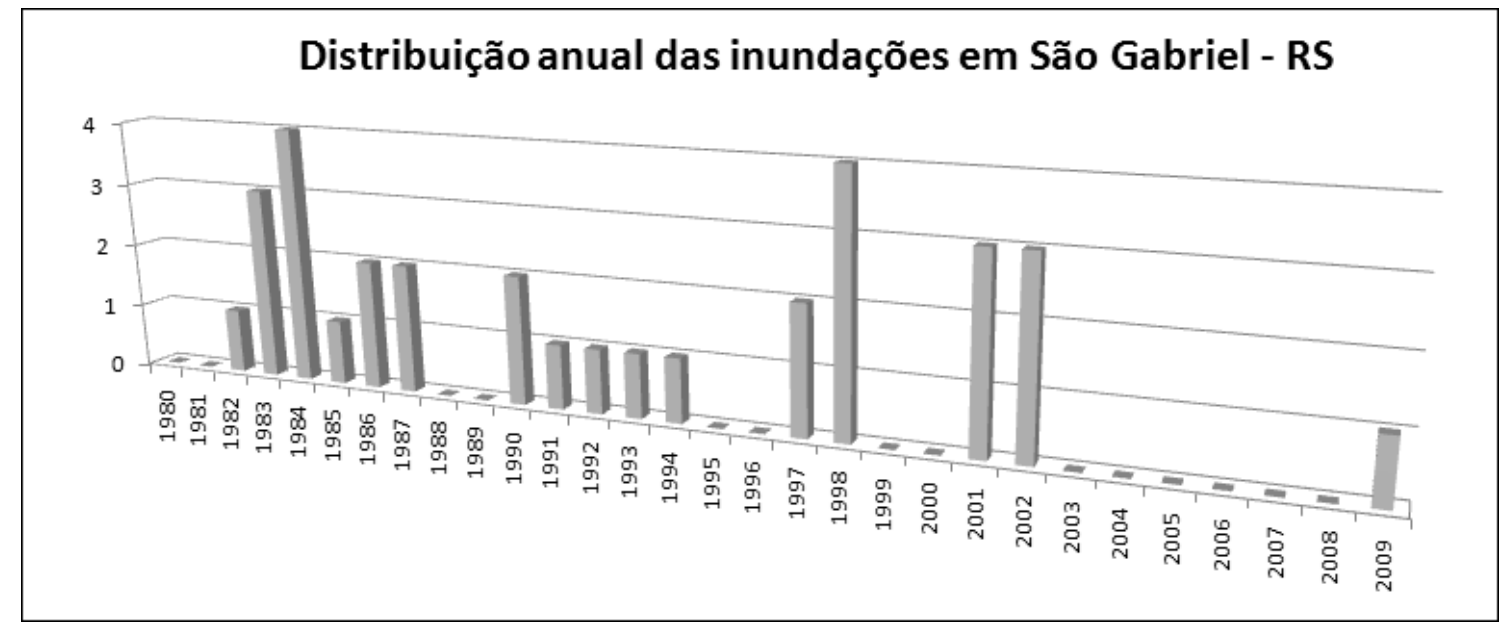

Figura 2: Gráfico da distribuição anual das inundações.

Com relação à incidência mensal e à significância do evento, os dados indicam que os meses de abril e novembro são os mais importantes, pois são os que mais apresentaram ocorrências de inundações e, também, com maior número de decretos de situação de emergência no município.

$\mathrm{Na}$ análise espacial dos eventos, foram identificados três bairros atingidos (Figura 3): Bairro Vila Maria, Bairro Baltar e Bairro Menino Jesus. O bairro Menino Jesus (1), está localizado mais ao norte, da área urbana, ao longo do rio. Este é o bairro mais vulnerável socialmente, com relação aos três bairros afetados. A fotografia de direção SW apresenta estas moradias mais precárias, rua sem calçamento e, ao fundo, é possível notar a mata ciliar do rio Vacacaí.

No bairro Baltar (2), a fotografia de direção NW mostra a Rua Clarestino Bento que é uma das ruas mais afetadas no bairro. As moradias foram colocadas no alto com muros em volta como preparação para a chegada das águas e rua sem calçamento.

Já no bairro Vila Maria (3), a fotografia de direção SW traz a Rua Celestino B. Filho, comumente afetada por inundações. Ao fundo, aparece a mata de galeria do rio Vacacaí. 


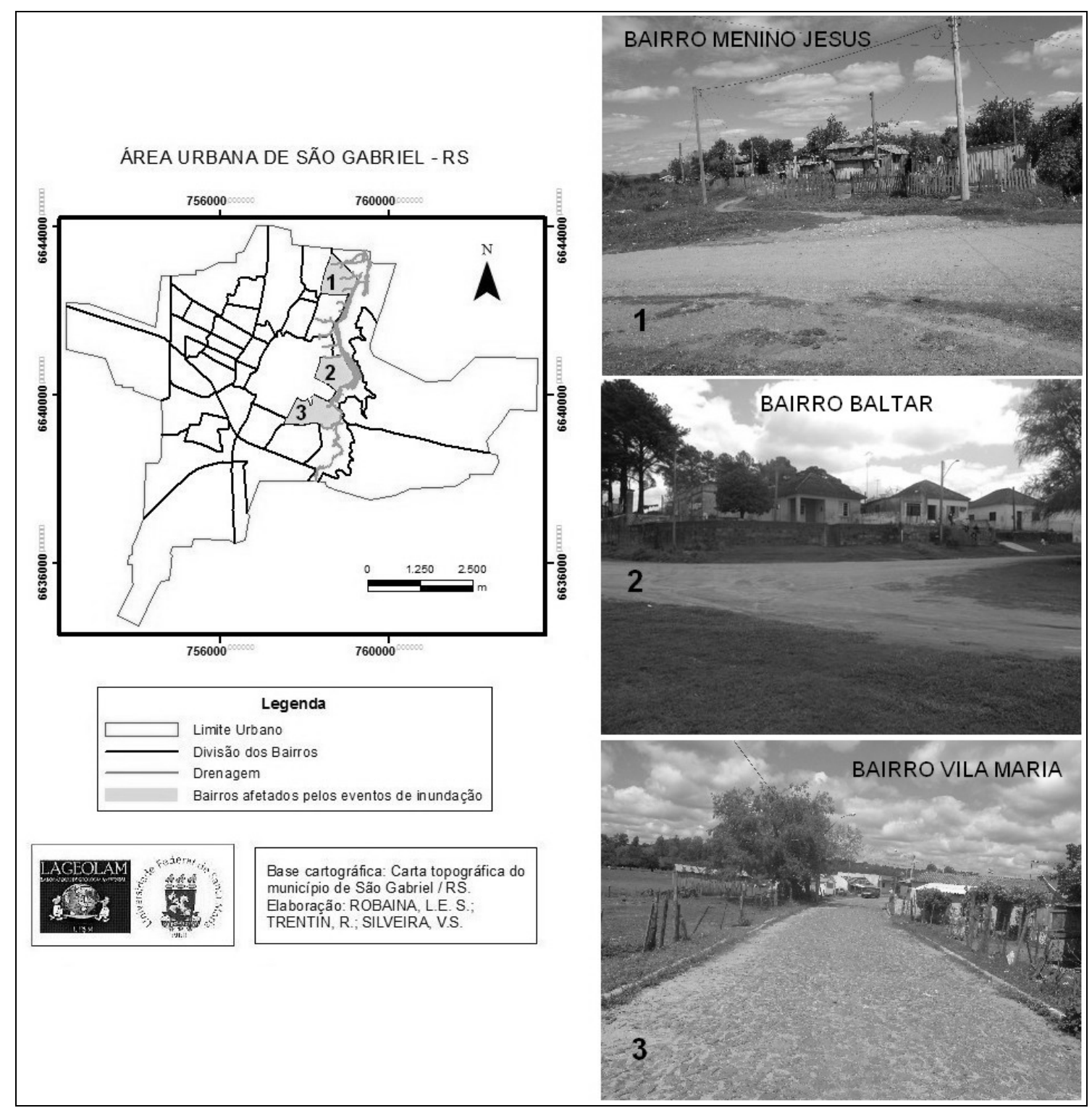

Figura 3: Mapa com a localização dos bairros afetados pelos eventos de inundação no município (fotografia em maio de 2011).

\section{Suscetibilidade às Inundações do Rio Vacacaí}

A bacia do Rio Vacacaí encerra cerca de $60 \%$ do território de São Gabriel, incluindo a totalidade da região da sede municipal. A definição e a caracterização do limite da área inundável do Rio Vacacaí no município apresentam feições de relevo típicas de áreas em que ocorrem inundações periódicas, ou seja, a rede hidrográfica da região desenvolveu amplas várzeas que, durante o período de cheias, permanecem alagadas. Os divisores de água são superfícies planas geralmente formadas por banhados que separam a drenagem de bacias hidrográficas secundárias.

Geo UERJ - Ano 15, no . 24, v. 1, $1^{\circ}$ semestre de 2013 p. 161-180 ISSN: $1415-7543$ E-ISSN: 1981-9021

http://www.e-publicacoes.uerj.br/index.php/geouerj 
Os levantamentos de campo permitiram determinar o limite de cheia das águas do rio. Definindo-se assim, que a cota máxima de inundação nos bairros Menino Jesus e Baltar é de 89 m, já no bairro Vila Maria, que apresenta um relevo mais plano, o limite máximo atingiu a cota de $91 \mathrm{~m}$.

A Figura 4 representa a espacialização da área de suscetibilidade às inundações do Rio Vacacaí nos três bairros afetados.

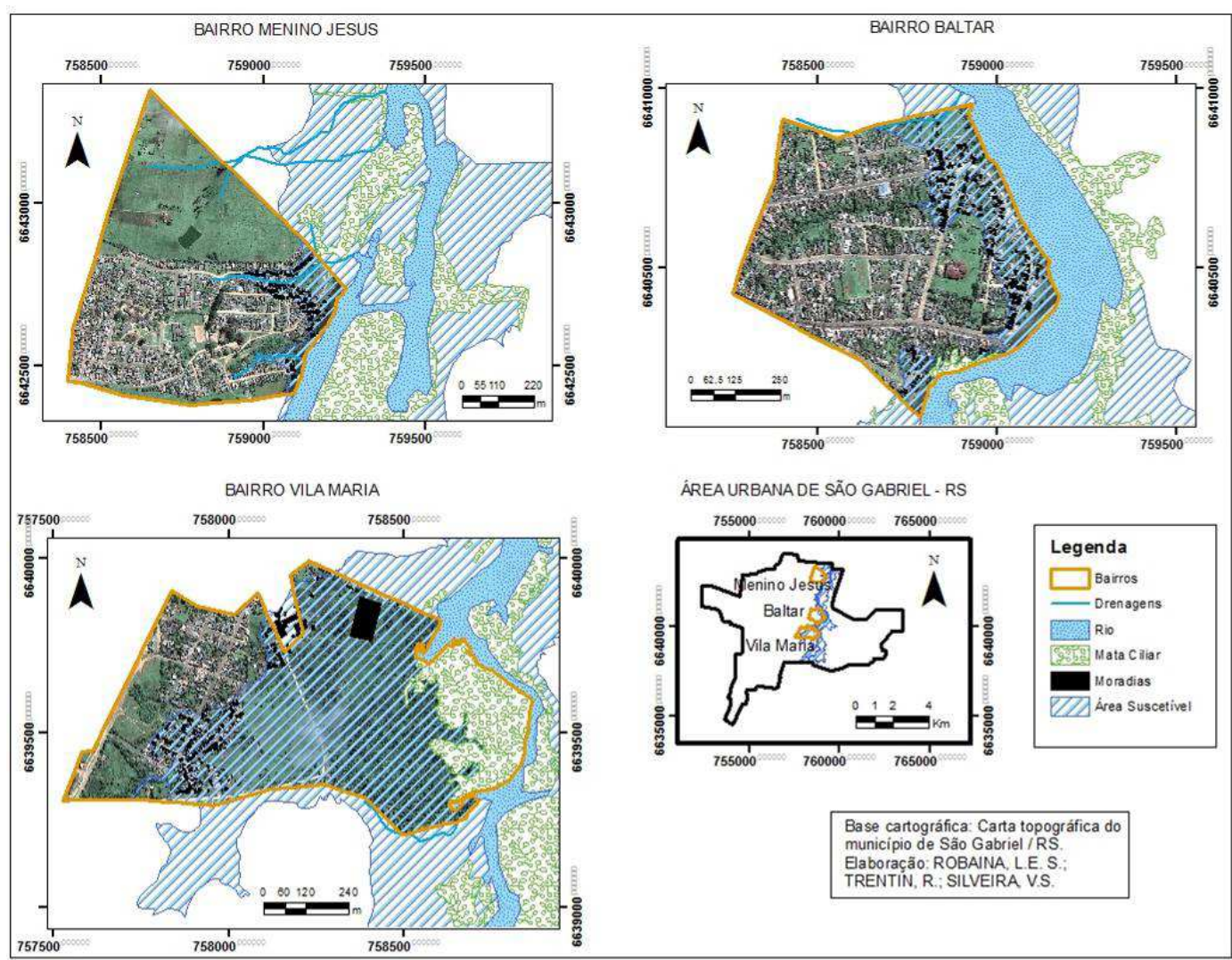

Figura 4: Mapa das áreas suscetíveis às inundações.

A suscetibilidade é definida como a área da porção urbana afetada por inundações, sendo definida por uma linha contínua ao longo do rio Vacacaí.

Na margem direita, do rio Vacacaí, a suscetibilidade cobre uma área de 1,93 $\mathrm{km}^{2}$, sendo que, nesta margem, a ocupação urbana ainda não está inserida, ocorrendo somente uso agrícola.

Na margem esquerda do rio Vacacaí, os processos de inundação ocupam uma área de $1,64 \mathrm{Km}^{2}$ de faixa contínua. Nesta margem, há ocupações por moradias que são atingidas nos períodos de cheias, causando diversos danos.

Geo UERJ - Ano 15, no. 24, v. 1, $1^{\circ}$ semestre de 2013 p. 161-180

ISSN: 1415-7543 E-ISSN: 1981-9021

http://www.e-publicacoes.uerj.br/index.php/geouerj 
Assim, soma-se uma área total de suscetibilidade no perímetro urbano de 3,57 $\mathrm{Km}^{2}$, sendo que a área total urbana do município é de $46,03 \mathrm{Km}^{2}$, as áreas de suscetibilidade representam $7,75 \%$ de toda área urbana.

\section{Definição do Perigo de Inundações}

Com o levantamento histórico, verificamos que os bairros afetados pelos eventos apresentam registros ao longo dos anos. Para a definição das classes de perigo, usamos como referência as Áreas de Proteção Permanente. Segundo o Código Florestal (Lei $\mathrm{n}^{\mathrm{o}}$ 4.771, de 15/09/65, alterada pela Lei n ${ }^{0} 7.803$, de 8/08/93), no seu Artigo $2^{\circ}$, Áreas de Proteção Permanente são locais onde devem ser mantidas todas as florestas e demais formas de vegetação natural. Estes locais foram definidos como de proteção especial, pois representam áreas frágeis ou estratégicas em termos de conservação ambiental, não devendo ser modificadas para outros tipos de ocupação. A manutenção da vegetação natural nestes locais contribui para o controle de processos erosivos e de assoreamento dos rios, para garantir qualidade dos recursos d'água e mananciais e para a proteção da fauna local.

Assim, definiu-se uma faixa de 100 metros de largura ao longo do Rio Vacacaí, como a Área de Proteção Permanente. Com a definição das áreas de perigo de inundação, foi possível estabelecer a probabilidade de ocorrência em duas classes: baixo e alto perigo a inundações.

As áreas de baixo perigo estão dentro da faixa de suscetibilidade, porém fora das áreas definidas como proteção permanente. Essas áreas somam-se 0,40 $\mathrm{Km}^{2}$, sendo caracterizadas pela predisposição a inundações de baixa frequência.

As áreas com alto perigo de inundações encontram-se dentro do limite de $100 \mathrm{~m}$ das Áreas de Proteção Permanente. Essas áreas ocupam 0,22 Km² e são caracterizadas pela ocorrência de inundações de mais alta frequência.

Assim, as áreas de perigo somam $0,62 \mathrm{Km}^{2}$, representando $17,36 \%$ dentro da suscetibilidade e 1,34\% em comparação com a área urbana do município.

A distribuição espacial das áreas com risco de inundação pode ser observada no mapa da figura 5 .

Geo UERJ - Ano 15, no. 24, v. 1, $1^{\circ}$ semestre de 2013 p. 161-180

ISSN: 1415-7543 E-ISSN: 1981-9021

http://www.e-publicacoes.uerj.br/index.php/geouerj 


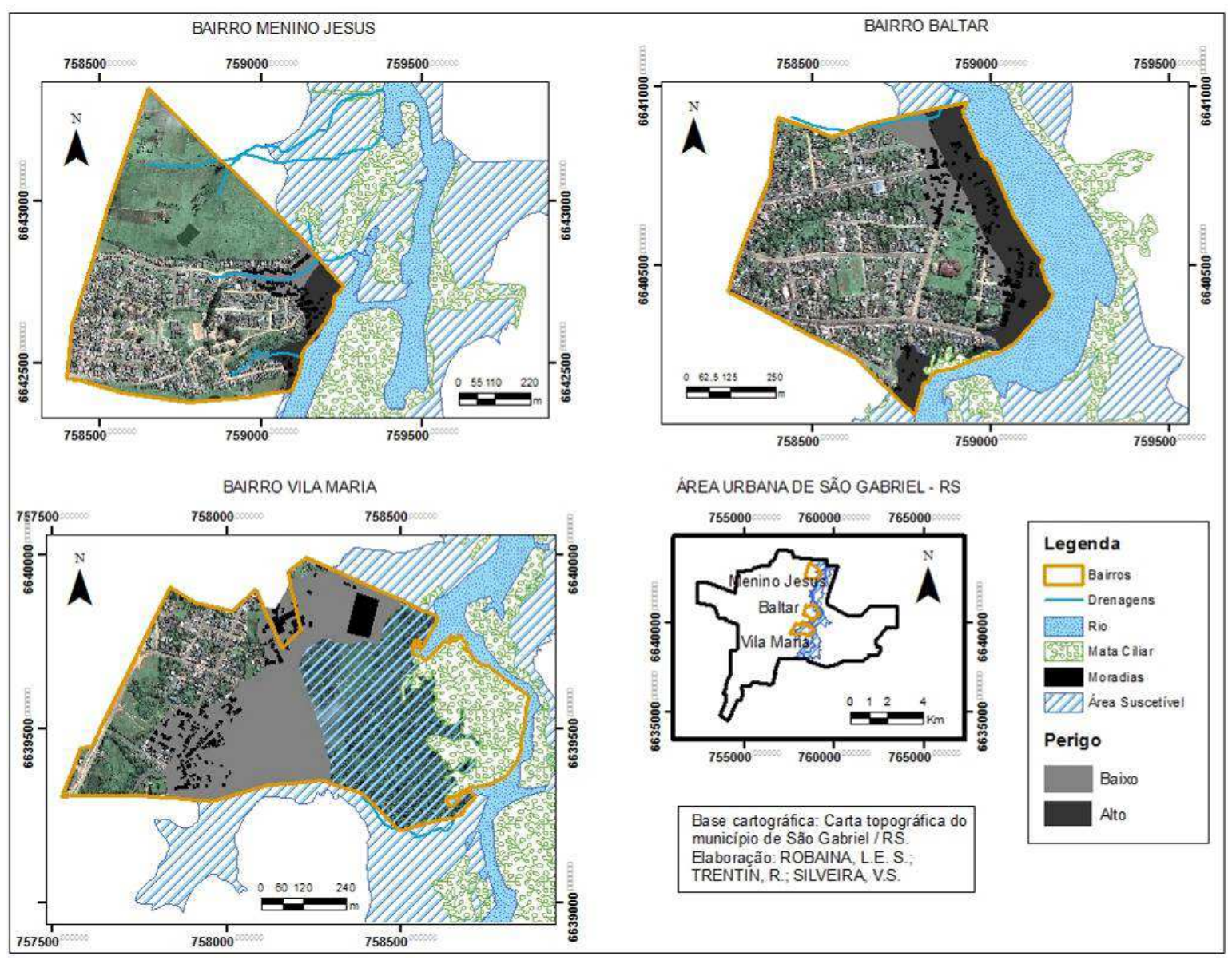

Figura 5: Mapa das áreas com perigo de inundações.

\section{Definição da Vulnerabilidade à Inundações}

A definição das áreas com vulnerabilidade a inundações permitiu estabelecer três classes: baixa, média e alta vulnerabilidade a inundações.

O bairro Vila Maria, além de sofrer com as inundações diretas do Rio Vacacaí, ainda é afetado pelas inundações dos arroios que cortam o bairro. Os principais problemas estão nas ruas Homero Veiga de Macedo e Celestino B. Filho. As ruas não possuem calçamento, as moradias apresentam médio padrão das construções e o adensamento é baixo. Estas características conferem baixa vulnerabilidade ao bairro.

No bairro Baltar, as moradias são altas com muros em volta como preparação para a chegada das águas, principalmente na localidade de Passo da Lagoa. Neste local, as moradias são definidas como médio a baixo padrão. As ruas do bairro não apresentam calçamento, sendo que as mais atingidas pela inundação são a Clarestino 
Bento e a Rua Alfredo Porcincula. Esta última pode ser definida como marca da cota de maior cheia do Rio Vacacaí.

O Bairro Menino Jesus, que inclui as localidades de Beira Rio e Pró-Mar, é um dos bairros mais pobres do município. Localiza-se bem ao norte da área ao longo do rio e muito próximo da margem. Há esgoto a céu a aberto e ruas sem calçamento. Neste bairro, houve o diagnóstico do padrão mais baixo de moradias em comparação com outros bairros afetados, definindo-se alta vulnerabilidade.

A distribuição espacial das áreas suscetíveis a inundação com as três classes de vulnerabilidade definidas pode ser observada no mapa da Figura 6.

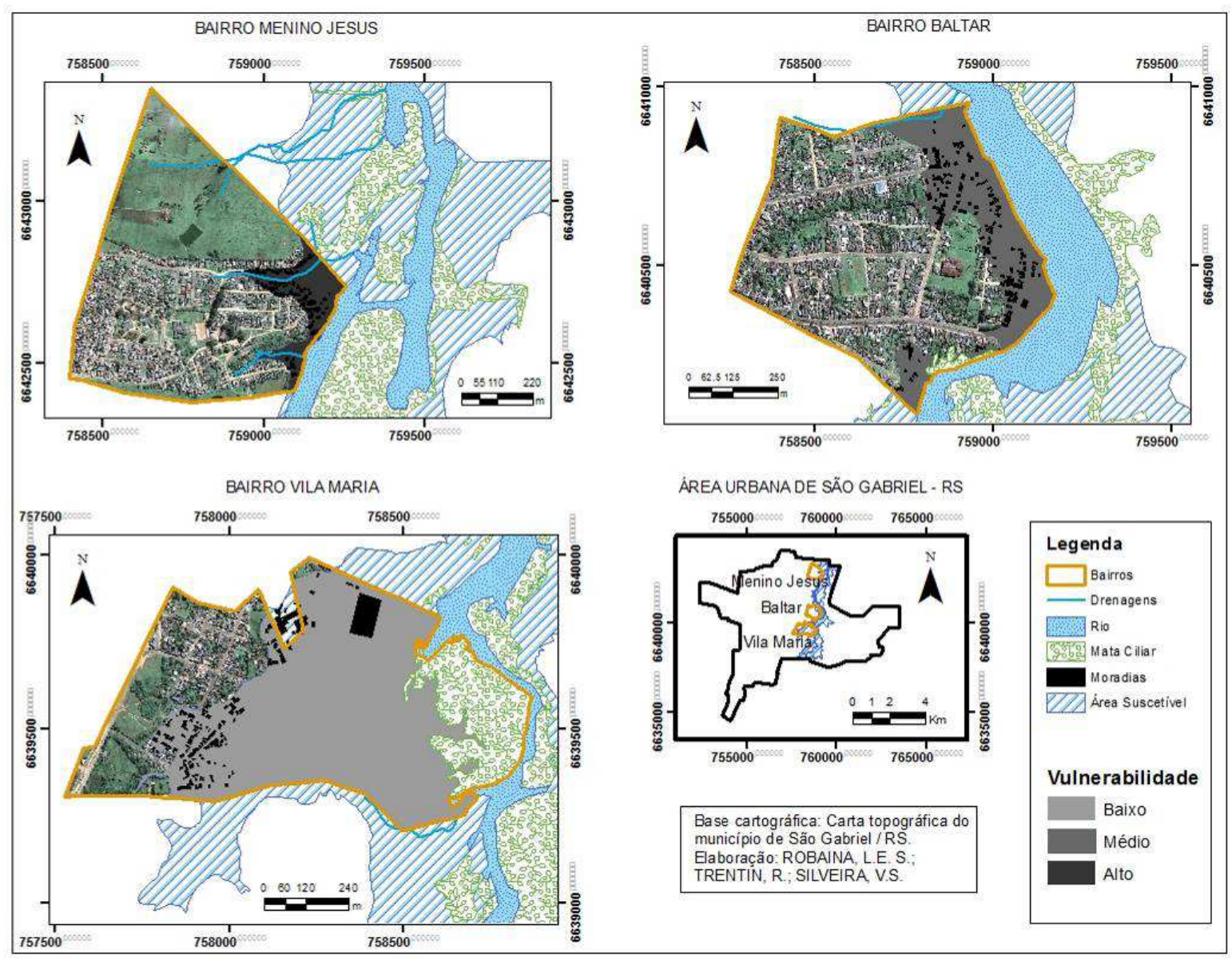

Figura 6: Mapa das áreas suscetíveis a inundação com as classes de vulnerabilidade.

\section{Áreas de Risco de Inundações}


A partir da relação entre as áreas de perigo e vulnerabilidade, apresentadas na metodologia, foram definidas quatro classes de risco: baixo, médio, alto e muito alto risco de inundações.

A área com baixo risco de inundações ocupa área de 0,20 km². Esta área está localizada no bairro Vila Maria, onde os parâmetros de perigo e a vulnerabilidade são caracterizados como baixos. Ou seja, nestas áreas existe uma baixa probabilidade de ocorrência de inundações e são esperadas baixas consequências de danos e prejuízos.

A área com médio risco a inundações ocupa área de $0,03 \mathrm{~km}^{2}$, está no bairro Baltar, atingindo residências de média vulnerabilidade pela presença de algumas obras de contenção das inundações, como é o caso de muros e aterros. Nessas áreas existe baixa probabilidade de ocorrência de inundações e são esperadas médias ou altas consequências de danos e prejuízos pela vulnerabilidade da população residente.

As áreas com alto risco a inundações ocupam área de $0,11 \mathrm{~km}^{2}$, localizam-se no bairro Baltar e bairro Menino Jesus. Caracterizam-se como áreas urbanas com alta probabilidade de ocorrência de inundações e onde são esperadas médias consequências de danos e prejuízos pela maior capacidade da população em enfrentar o problema.

A área com muito alto risco a inundações ocupa área de $0,02 \mathrm{~km}^{2}$, é a área com o mais baixo padrão de moradias, localizada no bairro Menino Jesus, onde a área urbana aproxima-se mais da margem direita do Rio Vacacaí. Representam áreas urbanas com alta probabilidade de ocorrência de inundações, onde são esperadas altas ou muito altas consequências de danos a prejuízos.

A distribuição espacial do zoneamento das áreas com risco de inundação, na área urbana de São Gabriel, pode ser observada no mapa da Figura 7. 


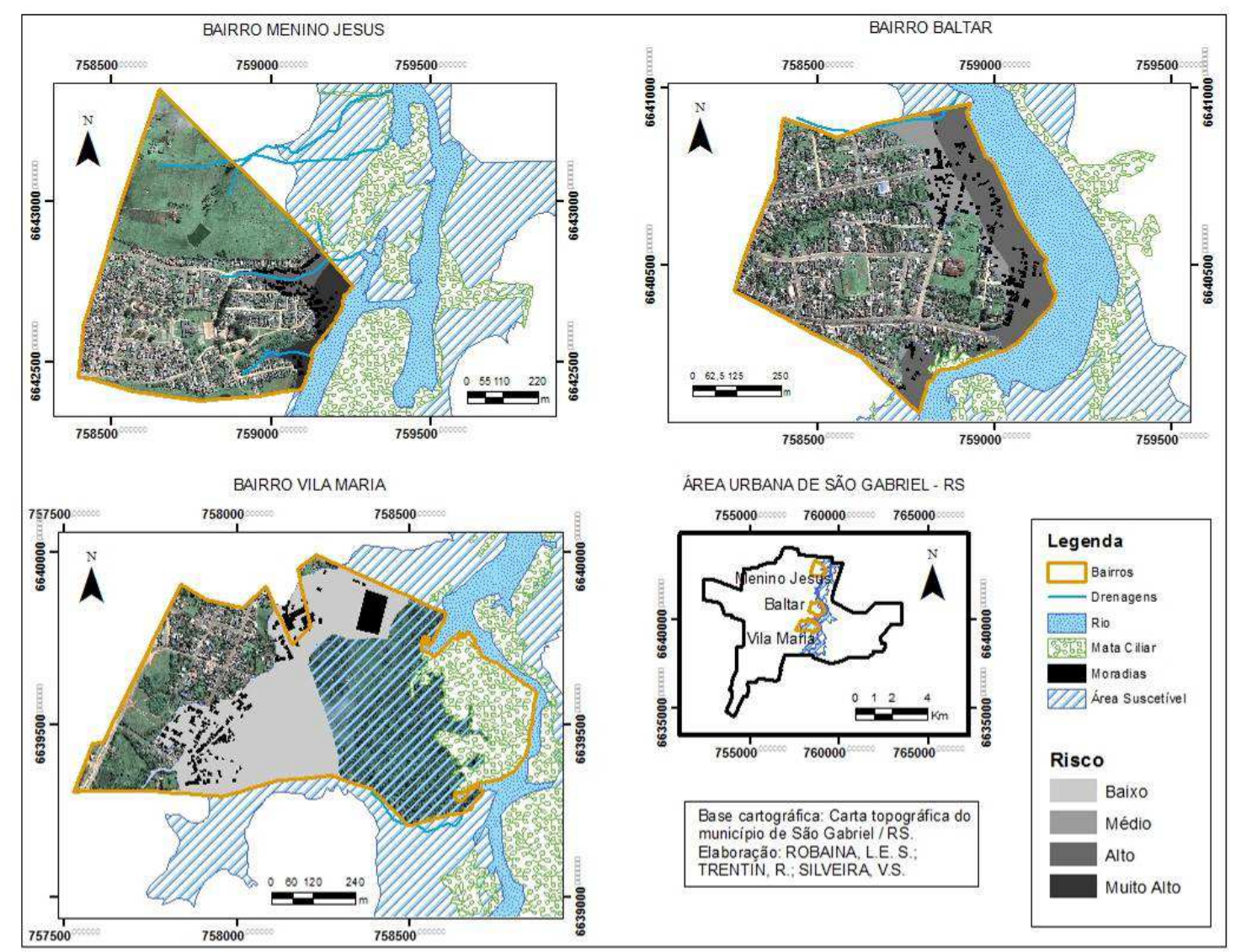

Figura 7: Mapa das áreas com risco de inundações.

\section{CONSIDERAÇÕES FINAIS}

A partir destes levantamentos de dados e da sua análise quanto aos processos de inundação ocorridas no município de São Gabriel, no Estado do Rio Grande do Sul, foi possível compreender melhor a dinâmica destes eventos no município.

O trabalho de zoneamento identificou quatro graus de risco na área urbana do município de São Gabriel. O baixo risco encontra-se no bairro Vila Maria, onde a probabilidade de ocorrência de inundações é baixo e a população apresenta uma vulnerabilidade média à baixa; o médio risco foi identificado no bairro Baltar onde a probabilidade e ocorrência de inundação é baixa e a vulnerabilidade da população é predominantemente média; o alto risco foi encontrado nos bairros Baltar e Menino Jesus onde o perigo de ocorrência de inundação é alto e; muito alto risco encontra-se no bairro Menino Jesus onde o perigo de ocorrência de evento é alto e a população é muito vulnerável, o que amplia os danos 
O entendimento dos conceitos e discussões feitas ao longo do trabalho é de grande importância para o início da contribuição de qualquer atividade de planejamento ambiental e gestão territorial, buscando a participação de todos os setores da sociedade.

Nas áreas determinadas como suscetíveis devem ser implementadas ações que evitem a ocupação ou tornem-nas de uso restrito, evitando-se, assim, o surgimento de novas áreas de risco com ocorrência de desastres.

Nas áreas de risco, as ações de gestão e planejamento devem buscar eliminar e/ou mitigar as perdas. Em alguns casos, reassentamentos devem ser avaliados. Em qualquer caso, é fundamental a participação, no planejamento das ações, da população envolvida.

\section{REFERÊNCIAS}

ALCÁNTARA-AYALA, I. Geomorphology, Natural Hazard, Vulnerability and Prevention of Natural Disasters in Developing Countries. Geomorphology, v. 47, n 2-4, p. 107-124, 2002

CASTRO, Antônio Luiz Coimbra de. Manual de Desastres. Brasília: [s.n.], 2003.

DAUPHINÉ, A. Risques et catastrophes. Observer, spatialiser, comprendre, gérer. Armand Colin, Coll. U, Paris, 2001.

DEYLE, R.E.; FRENCH, S.P.; OLSHANSKY, R.B. \& PATERSON, R.G. Hazard Assessment: The Factual Basis for Planning and Mitigation. In: CUTTER, S. (ed.). Cooperating with Nature. Confronting Natural Hazards with Land-Use Planning for Sustainable Communities. Washington, D.C. Joseph Henry Press. 1998

INSTITUTO BRASILEIRO DE GEOGRAFIA E ESTATÍSTICA. Censo 2010. Disponível em: < http://www.censo2010.ibge.gov.br/index.php>. Acesso em: 09 jan. 2012.

INSTITUTO GEOLÓGICO DE SÃO PAULO. Série Desastres Naturais. Disponível em: < http://www.igeologico.sp.gov.br> Acesso em: 09 jan. 2012.

INTERGOVERNMENTAL PANEL ON CLIMATE CHANGE (IPCC). Climate changes: The Physical Science Basis. Summary of Policymakers. Disponível em: http://www.ipcc.ch

JULIÃO, R.P.; NERY, F.;Ribeiro,J.L.; BRANCO, M.C.; ZÊZERE, J.L. Guia Metodológico para Produção de Cartografia Municipal de Risco e para Criação de Sistemas de Informação Geográfica (SIG) de base Municipal. Porto/Portugual: Autoridade Nacional de Proteção Civil. 2009 
KOBIYAMA, M.; MENDONÇA, M.; MORENO, D.A.; MARCELINO, I.P.V.O.; MARCELINO, E.V.; GONÇALVES, E.F.; BRAZETTI, L.L.P.; GOERL, R.F.; MOLLERI, G.S.F.; RUDORFF, F.M. Prevenção de Desastres Naturais: Conceitos Básicos. Curitiba: Ed. Organic Trading. 109 p. Disponível em http://www.labhidro.ufsc.br/publicações.html

MAIA, L. P. Geomorfologia Aplicada: Teoria e Prática. Mercator - Revista da Geografia da UFC, v. 1, n. 2, p. 133 - 137, 2002.

MATTEDI, M. A.; BUTZKE, I. C. A Relação entre o Social e o Natural nas Abordagens de Hazards e de Desastres. Ambiente \& Sociedade - ano IV - n. 9 - jul. dez. 2001.

MINISTÉRIO DAS CIDADES / INSTITUTO DE PESQUISAS TECNOLÓGICAS IPT - Mapeamento de riscos em encostas e margens de rios. Brasília: Ministério das Cidades; Instituto de Pesquisas Tecnológicas - IPT, 2007.

OJEDA, A. Crecidas e Inundaciones como Riesgo Hidrológico un Planteamiento Didáctico. Universidad del País Vasco. Lurralde. 1997

OLIVEIRA, E. L. de A. Áreas de risco geomorfológico na bacia hidrográfica do arroio Cadena, Santa Maria-RS: zoneamento e hierarquização. 2004. 147f. Dissertação (Mestrado em Geografia) - Universidade Federal do Rio Grande do Sul, Porto Alegre, 2004.

PELOGGIA, A. O Homem e o Ambiente Geológico: geologia, sociedade e ocupação urbana no município de São Paulo. São Paulo: Xamã, 1998, 271p.

PREFEITURA MUNICIPAL DE SÃO GABRIEL. Plano diretor do município de São Gabriel. Disponível em: < http://www.sãogabriel.rs.gov.br> Acesso em: 24 jan. 2012.

RECKZIEGEL, Bernadete. Relação dos desastres naturais registrados em municípios do estado do rio grande do sul no período de 1980 a 2005. 2007. $261 \mathrm{f}$. Dissertação (Mestrado em Geociências)-Universidade Federal de Santa Maria, Santa Maria, 2007.

SOUZA, C.r.G. Flooding in the São Sebastião Region, Northern Coast of São Paulo State, Brazil. Anais da Academia Brasileira de Ciências, 70 (2): 353-366, 1998

TOMINAGA, Lídia Keiko; SANTORO, Jair; AMARAL, Rosangela (Org.). Desastres Naturais: Conhecer para Prevenir. São Paulo: Instituto Geológico, 2009.

TUCCI, C. E. M. Curso de Gestão das Inundações urbanas. 2005.

UNITED NATIONS DISASTER RELIEF OFFICE.UNDRO's (UNDRO). Approach to Disaster Mitigation. UNDRO News, jan.-febr.1991.Geneva: Office of the United Nations Disasters Relief Co-ordinator. 20p., 1991. 
UNITED NATIONS INTERNATIONAL STRATEGY FOR DISASTER REDUCTION (UM-ISDR) - Living with Risk. A Global Review of Disaster Reduction Initiatives, United Nations. Geneva, Suiça. 2002. Disponivel em: http://www.unisdr.org/eng/about_isdr/bd-lwr-2004-eng.htm.

VEYRET, Yvette (Org.). Os Riscos: o homem como agressor e vítima do meio ambiente. São Paulo: Contexto, 2007.

Artigo recebido para publicação em janeiro de 2013.

Artigo aceito para publicação em maio de 2013. 